\title{
Potential Hemoglobin A/F role in clinical Malaria
}

\author{
Vikky Awasthi ${ }^{1}$, Debprasad Chattopadhyay ${ }^{2} \&$ Jyoti Das $^{1 *}$
}

${ }^{1}$ Immunology Division, ICMR-National Institute of Malaria Research, Dwarka, New Delhi; Present Address: Regional Medical Research Centre, Belagavi, Nehru Nagar, National Highway No.4, Belagavi-590010, Karnataka, India.2ICMR Virus Unit, Calcutta, ID \& BG Hospital, GB 4, Beliaghata, Kolkata, India; Jyoti Das: E-mail - jyoti@mrcindia.org; Telephone: +91-25307203, Fax: +91-25307177; Corresponding author*

Received August 5, 2017; Revised August 18, 2017; Accepted August 19, 2017; Published August 31, 2017

\begin{abstract}
The Malarial parasite resides in the host RBC during its erythrocytic cycle. Plasmodium meets its entire nutritional requirement from RBC. It scavenges the hemoglobin of RBCs to meet its amino acid requirement. The host hemoglobin is made of different chains and it is dependent on age. Hemoglobin $\mathrm{F}(\mathrm{HbF})$, which has two-alpha and two gamma chain persists in children upto six years, and hemoglobin A ( $\mathrm{HbA})$ made of two alpha and two beta chains dominates. Therefore, it is of interest to compare the compositional features of $\mathrm{HbA}$ with $\mathrm{HbF}$. Isoleucine is present in hemoglobin of children (gamma chain of $\mathrm{HbF}$ ) while it is absent in adult hemoglobin $(\mathrm{HbA})$. The presence of Isoleucine (I) makes HbF ideally suitable for the growth of parasite, as it does not have to depend upon the exogenous supply of the isoleucine, which might be responsible for making children more vulnerable to malaria as compared to adults.
\end{abstract}

Keywords: Hemoglobin, Plasmodium falciparum, Amino acids, Malaria

\section{Background:}

Malaria is one of the most prevalent diseases in developing countries [1]. Malaria is caused by Plasmodium and over more than 200 species of Plasmodium has been identified. Four species of Plasmodium that causes malaria in humans are Plasmodium falciparum, Plasmodium vivax, Plasmodium malariae, Plasmodium ovale and recently, Plasmodium Knowleski have been reported to infect humans [2]. Malaria infection occurs when an infected mosquito bites a healthy host and injects sporozoites in blood stream. The sporozoite reaches liver and enters the hepatocytes, where it multiplies and forms merozoite, and these merozoites are released into the blood stream [3]. These merozoites infect the red blood cells (RBC). Parasite undergoes multiple division and morphological changes, which helps it to bypass immune invasions [4]. Plasmodium falciparum is responsible for deaths due to malaria [1]. Malaria parasite meets most of its nutritional requirements from blood. During replication hemoglobin is degraded to get amino acid required for growth [5]. Importance of amino acids on growth of Plasmodium has been as here discussed with reference to I (Isoleucine) [6], N (Asparagine) [7], M (methionine) [8] $\mathrm{R}$ (Arginine) [9] hibernation of Plasmodium [10]. Different Forms of hemoglobin's have been reported in the RBC according to human age [11]. Hemoglobin comprises of two alpha and two zetta or etta chains during ISSN 0973-2063 (online) 0973-8894 (print) embryonic stages when hematopoiesis starts in liver [12]. Later during the developmental stages hemoglobin having two alpha chains and two-gamma chain dominates. A significant amount of fetal hemoglobin persists upto eight months after birth. Most people have only trace amounts, if any, of fetal haemoglobin after infancy. The combination of two alpha genes and two beta genes comprises the normal adult haemoglobin, haemoglobin A whereas 5 Hemoglobin A2, is composed of two alpha chains and two delta chains and constitutes up to $3 \%$ of total hemoglobin in adults. The hemoglobin with different chains varies in amino acids composition, their oxygen carrying capacity as well as in their stability. Embryonic hemoglobin $(\mathrm{HbE})$ and $\mathrm{HbF}$ has better oxygen carrying capacity as compared to other hemoglobin types however the stability of $\mathrm{HbE}$ is lower as compared to adults Hbs. Parasites are totally dependent upon hemoglobin to replicate in the host. Therefore, it is of interest to study importance of $\mathrm{Hb}$ in RBC.

Malaria affects all age groups. However, the children are affected the most. According to WHO report there were an estimated 438 000 malaria deaths around the world in $2015,69 \%$ of total deaths due to malaria are known to occur in children aged from 6 months to 5 years [1]. Children are considered to be most vulnerable groups in human population, Severe anaemia, 
hypoglycaemia and cerebral malaria are the features of severe malaria more commonly seen in children than in adults [13].

Though the parasite culture in $\mathrm{RBC}$ containing adult $\mathrm{Hb}$ is routinely performed [14] The studies on parasite culture in RBCs containing $\mathrm{HbF}$ by different groups show contradictory results. Some research have suggested that growth of Plasmodium is retarded in $\mathrm{RBC}$ containing $\mathrm{HbF}$ [15] while some suggests that under conditions of high oxygen the Plasmodium shows preference to RBC containing HBF with vigorous growth [16]. The inhibition of parasite growth in $\mathrm{HbF}$ has been due to factors present in mother's plasma [16].

In this study, we show the abundance of different amino acids in Plasmodium falciparum 3D7 and distribution of different amino acids according to its essential nature in host. We have also compared the amino acid composition of different chains of haemoglobin to determine the difference that leads to preference of $\mathrm{RBC}$ containing $\mathrm{HbF}$, which might explain the disease severity in children.

\section{Methodology:}

The FASTA format of all protein sequence, 5,369 proteins, of Plasmodium was downloaded from PlasmoDB. Composition of protein sequences was completed using ProtParaman tool. ProtParaman tool is an online tool, which is freely available and determines the sequence composition and predicts other physical parameters [17]. Total amino acid composition was compiled using Microsoft Excel. The Charts and graphs were made using Microsoft excel. MSA of haemoglobin chains was performed using Clustal Omega tool from the EMBL-EBI Web Services [18].

Table 1: Dataset. The table lists the amino acid residues present in total protein of Plasmodium falciparum (A), essential amino acids (B), conditionally essential amino acid(C) and non-essential amino acid (D) residues present in Plasmodium falciparum.

\begin{tabular}{|c|c|}
\hline (A) Amino Acid Residue & Number of Residue \\
\hline ALA (A) & 82537 \\
\hline CYS (C) & 73987 \\
\hline ASP (D) & 270290 \\
\hline GLU (E) & 183037 \\
\hline PHE (F) & 298756 \\
\hline GLY (G) & 118471 \\
\hline HIS $(\mathrm{H})$ & 100949 \\
\hline ILE (I) & 387902 \\
\hline LYS (K) & 491170 \\
\hline LEU (L) & 318735 \\
\hline MET (M) & 91797 \\
\hline ASN (N) & 600456 \\
\hline PRO (P) & 83223 \\
\hline GLN (Q) & 115618 \\
\hline ARG (R) & 110769 \\
\hline SER (S) & 267090 \\
\hline THR (T) & 171384 \\
\hline VAL (V) & 159380 \\
\hline TRP (W) & 20830 \\
\hline TYR (Y) & 238546 \\
\hline (B) Essential amino acid & Number of residues \\
\hline Histidine $(\mathrm{H})$ & 100949 \\
\hline Isoleucine (I) & 387902 \\
\hline Leucine (L) & 318735 \\
\hline Methionine(M) & 91797 \\
\hline Phenylalanine $(\mathrm{F})$ & 298756 \\
\hline Threonine (T) & 171384 \\
\hline Tryptophan (W) & 20830 \\
\hline Valine(V) & 159380 \\
\hline Lysine (K) & 491170 \\
\hline (C) Conditionally essential amino acid & Number of residues \\
\hline Arginine $(R)$ & 110769 \\
\hline Asparagine $(\mathrm{N})$ & 600456 \\
\hline Glutamine (Q) & 183037 \\
\hline Glycine $(G)$ & 118471 \\
\hline Proline $(\mathrm{P})$ & 83223 \\
\hline Serine $(S)$ & 267090 \\
\hline Tyrosine $(\mathrm{Y})$ & 238546 \\
\hline (D) Non-essential amino acid & Number of residues \\
\hline Alanine (A) & 82537 \\
\hline Aspartate (D) & 270290 \\
\hline Cysteine $(\mathrm{C})$ & 73987 \\
\hline Glutamate (E) & 183037 \\
\hline
\end{tabular}




\section{BIOINFORMATION}

Discovery at the interface of physical and biological sciences

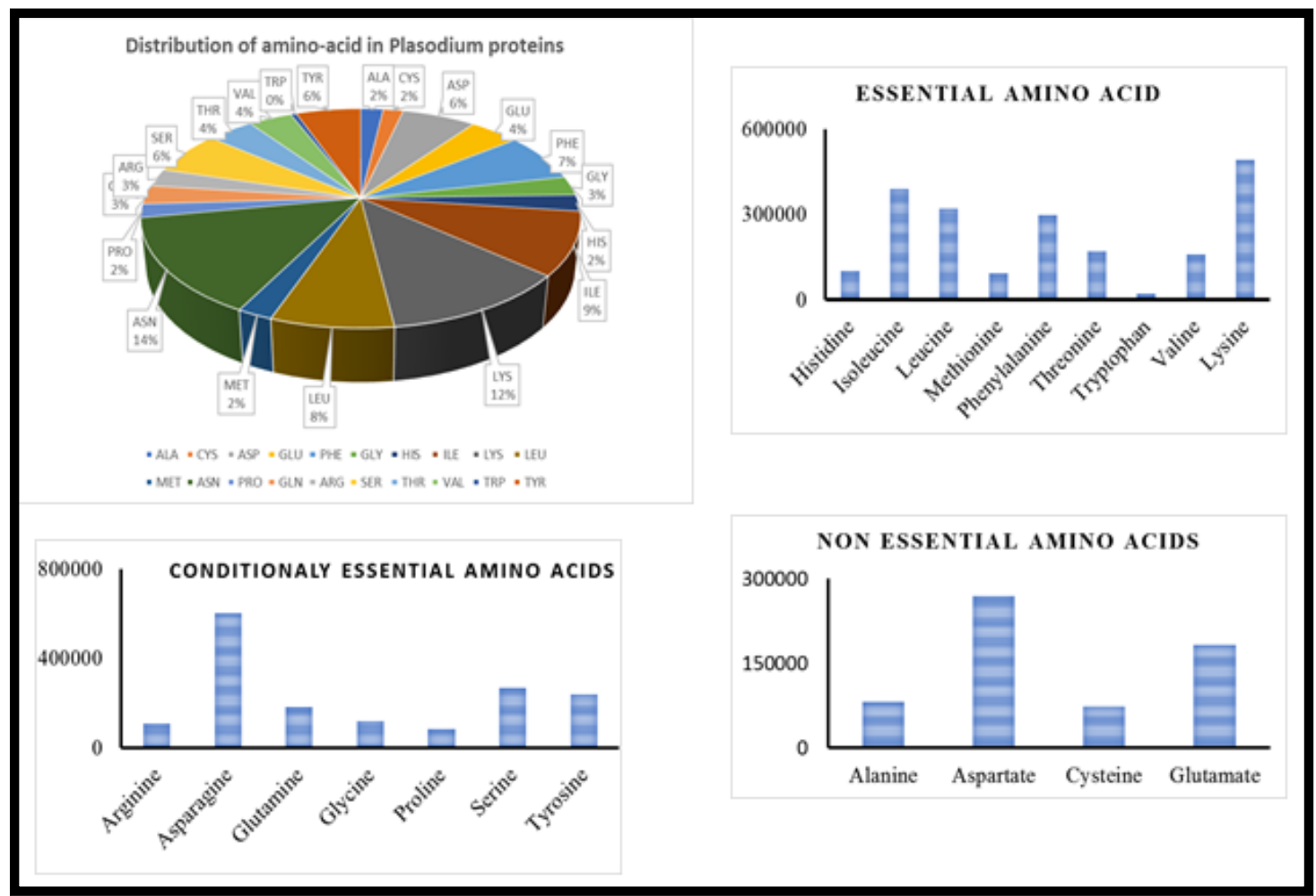

Figure 1: Abundance of amino-acid in total protein of Plasmodium. Sequences of all the 5639 proteins of Plasmodium were downloaded and abundance of amino acids were determined for individual protein by ProtParaman tool. The pie chart represents the abundance of the amino acids (A).The distribution of amino acids in Plasmodium proteins on the basis of essential (B), conditionally essential (C) and non-essential amino acids (D).

\begin{tabular}{|c|c|}
\hline Gamma-1 & MGHFTEE DKATITSLWGKVN--VEDA \\
\hline Epsilon & MVHFTAEEKAAVTSLWSKMN--VEEA \\
\hline Delta & MVHLTPEEKTAVNALWGKVN--VDF \\
\hline Beta & MVHLTPEEK SAVTALWGKVN--VDEV \\
\hline Alpha & -MVLS PADKT NV KAAWG KV GAHAG \\
\hline Zeta-2 & -MSLT KTERTIIVSMWAKISTQAD \\
\hline Gamma-1 & P KV KAH GK KVLTS LGDAT KH LDDLKG \\
\hline Epsilon & P KV KAH GK KVLTS FG DAI KNMDNLK P \\
\hline Delta & P KV KAH GK KV LGA FS DGLAH LDNLKG \\
\hline Beta & P KV KAHGK KV LGA FS DGLAH LDNLKG \\
\hline Alpha & AQVKGH GK KVADA LTNAVAHVDDMPI \\
\hline Zeta-2 & AQLRAHGS KVVAAVGDAVKS IDDIGC \\
\hline Gamma & FGKE FTPEVQA SWQ KMVTAVA SALSSR \\
\hline Epsilon & FGKE FT PEVQAAWQRLVSAVA IALAHKX \\
\hline Delta & FGKE FT PQMQAAYQRVVAGVANALAHK \\
\hline Beta & FGKE FT P PVQAAYQRVVAGVANALAHK \\
\hline Alpha & LPAE FTP AVHA SLDKFLASVS TVLTSK \\
\hline Zeta & FPADFTAEAHAAWDKFLSVVSSVLTE \\
\hline
\end{tabular}

Figure 2: Multiple sequence alignment of amino acid sequence of different chains of hemoglobin gamma (NP_000550.2) Epsilon (NP_005321.1), Delta (NP_000510.1) Beta (NP_000509.1), Alpha (P69905.2), and Zeta (3W4U:E). Identical and similar amino acids are highlighted with similar font colors.

Results:

Abundance of Amino acids in parasite:
Complete protein sequences of 5369 were downloaded from PlasmoDB for Plasmodium falciparum 3D7. The amino acid 
compositions of total 5369 proteins are represented by pie chart (Figure 1A). As The amino-acid composition of Plasmodium falciparum proteins would suggest the co-relation between the amino-acids composition of haemoglobin and parasite proteins. The most incorporated amino acid in Plasmodium protein is $\mathrm{N}$ $(13 \%), \mathrm{K}(12 \%)$ and I (9\%). We further analysed amino acids composition of Plasmodium protein according to the amino acid requirement by the host i.e. essential amino acids (Figure 1B), conditionally essential amino acids (Figure 1C) and non-essential amino acid (Figure 1D). It was observed that the essential and conditionally essential amino acids are widely incorporated in the Plasmodium proteins as compared to non-essential amino acids.

\section{Distribution of amino acids in Haemoglobin chains:}

The protein sequence of the haemoglobin chain was downloaded from NCBI and the composition of amino acid was determined using ProtParaman tool [17] as described above.

The fasta formats for different chain of the haemoglobins were obtained from NCBI. The assertion number of different chains of are as follows:

\section{NP_000550.2 hemoglobin subunit gamma:}

MGHFTEEDKATITSLWGKVNVEDAGGETLGRLLVVYPWTQR FFDSFGNLSSASAIMGNPKVKAHGKKVLTSLGDATKHLDDLK GTFAQLSELHCDKLHVDPENFKLLGNVLVTVLAIHFGKEFTPE VQASWQKMVTAVASALSSRYH

NP_005321.1 hemoglobin subunit epsilon

MVHFTAEEKAAVTSLWSKMNVEEAGGEALGRLLVVYPWTQ RFFDSFGNLSSPSAILGNPKVKAHGKKVLTSFGDAIKNMDNLK PAFAKLSELHCDKLHVDPENFKLLGNVMVIILATHFGKEFTPE VQAA WQKLVSAVAI ALAHKYH

\section{NP_000510.1 hemoglobin subunit delta [Homo sapiens]} MVHLTPEEKTAVNALWGKVNVDAVGGEALGRLLVVYPWTQ RFFESFGDLSSPDAVMGNPKVKAHGKKVLGAFSDGLAHLDN

\section{LKGTFSQLSELHCDKLHVDPENFRLLGNVLVCVLARNFGKEF TPQMQAAYQKVVAGVANALAHKYH}

NP_000509.1 hemoglobin subunit beta [Homo sapiens] MVHLTPEEKSAVTALWGKVNVDEVGGEALGRLLVVYPWTQ RFFESFGDLSTPDAVMGNPKVKAHGKKVLGAFSDGLAHLDN LKGTFATLSELHCDKLHVDPENFRLLGNVLVCVLAHHFGKEF TPPVQAAYQKVVAGVANALAHKYH

P69905.2 Hemoglobin subunit alpha MVLSPADKTNVKAAWGKVGAHAGEYGAEALERMFLSFPTTK TYFPHFDLSHGSAQVKGHGKKVADALTNAVAHVDDMPNAL SALSDLHAHKLRVDPVNFKLLSHCLLVTLAAHLPAEFTPAVH ASLDKFLASVSTVLTSKY

\section{W4U_E | PDBID | CHAIN | SEQUENCE-zeta}

MSLTKTERTIIVSMWAKISTQADTIGTETLERLFLSHPQTKTYFP HFDLHPGSAQLRAHGSKVVAAVGDAVKSIDDIGGALSKLSEL HAYILRVDPVNFKLLSHCLLVTLAARFPADFTAEAHAAWDKF LSVVSSVLTEKYR

Multiple sequence analysis of different chain of Hemoglobin was done using Clustal omega. The results show similarity between different chains of haemoglobin. Further, we looked at the distribution of amino acid in different haemoglobin chain (Table 1). We observe that the amino acid composition varies in different chains. None of the chains of Haemoglobin A (two alpha chains, and two beta chains) and Hemoglobin $\mathrm{A}_{2}$ (two alpha and two delta chains) contain I, an essential amino acid, in both alpha and delta chain. While Isoleucine is present in gamma chain haemoglobin F, (two gamma chains and two beta chains), Zeta and epsilon chain which forms part of $\mathrm{HbE}$ (Embryonic haemoglobin). This result show that I, which is an essential amino acid, comprises about $9 \%$ of total amino acids present in Plasmodium. Absence of this amino acid from $\mathrm{Hb}$ forces the parasite to rely upon exogenous supply of this amino acid, which may retard its growth.

Table 2: Table showing the distribution of different amino acids in different chains of haemoglobin.

\begin{tabular}{|l|l|l|l|l|l|l|l|l|l|l|l|l|l|l|l|l|l|l|l|l|l|}
\hline Hb SUBUNIT & A & C & D & E & F & G & H & I & K & L & M & N & P & Q & R & S & T & V & W & Y & \\
\hline GAMMA & 12 & 1 & 8 & 8 & 8 & 12 & 7 & 3 & 12 & 17 & 3 & 5 & 4 & 4 & 3 & 11 & 11 & 13 & 3 & 2 & 147 \\
\hline EPSILON & 17 & 1 & 5 & 9 & 9 & 9 & 7 & 5 & 14 & 16 & 4 & 7 & 6 & 3 & 2 & 9 & 6 & 13 & 3 & 2 & 147 \\
\hline DELTA & 15 & 2 & 7 & 7 & 8 & 13 & 7 & 0 & 11 & 18 & 3 & 8 & 6 & 5 & 4 & 6 & 5 & 17 & 2 & 3 & 147 \\
\hline BETA & 15 & 2 & 7 & 8 & 8 & 13 & 9 & 0 & 11 & 18 & 2 & 6 & 7 & 3 & 3 & 5 & 7 & 18 & 2 & 3 & 147 \\
\hline ALPHA & 21 & 1 & 8 & 4 & 7 & 7 & 10 & 0 & 11 & 18 & 3 & 4 & 7 & 1 & 2 & 11 & 9 & 13 & 1 & 3 & 141 \\
\hline ZETA & 16 & 1 & 8 & 6 & 7 & 6 & 7 & 7 & 9 & 17 & 2 & 1 & 5 & 3 & 6 & 13 & 12 & 11 & 2 & 3 & 142 \\
\hline
\end{tabular}

\section{Discussion:}

Plasmodium parasite, scavenges the haemoglobin to meets its amino acid requirements while lipids are obtained from RBCs membrane. The distribution of amino acids in the proteins of Plasmodium shows incorporation of all the 20 amino acids. However, the amino acids, which are essential and conditionally essential to the host, are present in higher percentage than nonessential amino acids.

Among the essential amino acids leucine is required most followed by isoleucine. Among the conditionally essential amino acids $\mathrm{N}$ is required the most. $\mathrm{N}$ is present in parasite as repeat which might have role in immune evasion by antigenic variation. Other amino acids like arginine, which is essential for polyamine synthesis is important for robust growth of the parasite.

I make up to $9 \%$ of total amino acids in Plasmodium falciparum has to be obtained exogenously from blood, as it is absent in adult haemoglobin. Istvan et al. has shown that the absence of I affects parasite growth and I analogue inhibits the parasite growth [19]. The gamma chain of foetal haemoglobin $(\mathrm{HbF})$ contains all the amino acids including I. Hence; the parasite residing in the foetal

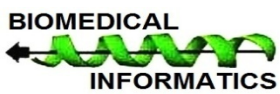


RBC does not require exogenous supply of isoleucine, which in turn might aid parasite to multiply exponentially. Study by Sauerzopf et.al., has shown that $P$. falciparum are equally permissive to growth in $\mathrm{HbF}$ and $\mathrm{HbA}$ in vitro further confirms that the growth of parasite will be aided by the presence of isoleucine. The percentage of $\mathrm{HbF}$ has been shown to be highest in foetus and $18 \%$ up to the age of 9 while in the age group of $10-$ 20 years its percentage falls to $8 \%[20,21]$. The presence of significant percentage of $\mathrm{HbF}$ up to the age of 9 might explain the venerability to malaria and death due to malaria.

\section{Conclusion:}

As Plasmodium solely depends upon the degradation of haemoglobin for its amino acid requirements it meets most of the nutritional requirements from haemoglobin. As $\mathrm{HbF}$ contains all the amino acids including isoleucine (absent in $\mathrm{HbA}$ ) required by the parasite hence, this might be aid growth of parasite in $\mathrm{HbF}$ containing RBC. Besides at the age of 9 up to, $18 \%$ of RBC contains $\mathrm{HbF}$. Hence, we hypothesise that presence of $\mathrm{HbF}$ would aid parasite growth leading to disease severity in children.

\section{Acknowledgement:}

We would like to thank, NIMR (ICMR) for funding the study.

\section{Conflict of Interest:}

Authors declare no conflict of Interest

\section{References:}

[1] http://www.who.int/malaria/publications/world_malaria _report/en/

[2] Daneshvar C et al. Clin. Infect. Dis. Off. Publ. Infect. Dis. Soc. Am. 2009 49: 852 [PMID 19635025]

[3] Prudêncio M et al. Nat. Rev. Microbiol. 2006 4: 849 [PMID
17041632]

[4] Cowman AF \& Crabb BS. Cell 2006 124: 755 [PMID: 16497586]

[5] Liu J et al. Proc. Natl. Acad. Sci. 2006 103: 8840[PMID: 16731623]

[6] Martin RE \& Kirk K. Blood 2007 109: 2217 [PMID: 17047158]

[7] Nagaraj VA et al. Nat. Commun. 2015 6: 8775[PMID: 26531182]

[8] Cobbold SA et al. Int. J. Parasitol. 2011 41: 125 [PMID: 20851123]

[9] Awasthi V et al. J Vector Borne Dis. 2017 54: 139 [PMID: 28748834]

[10] Babbitt SE et al. Proc. Natl. Acad. Sci. 2012 109: E3278 [PMID: 23112171]

[11] Bunn HF \& Forget BG. Hemoglobin: Molecular, Genetic and Clinical Aspects. 1986.

[12] Stamatoyannopoulos JA \& Nienhuis AW. Annu. Rev. Med. 1992 43: 497 [PMID: 1374600]

[13] Schumacher RF \& Spinelli E. Mediterr. J. Hematol. Infect. Dis. 2012 4(1): e2012073 [PMID: 23205261]

[14] Frederick L. Schuster Clin Microbiol Rev. 2002 15(3): 355. [PMID: 12097244]

[15] Amaratunga C et al. Malaria. PLOS ONE. 2011 6: e14798 [PMCID: PMC3075246]

[16] Sauerzopf U et al. Malar. J. 2014 13: 436 [PMID: 25406504]

[17] http://web.expasy.org/protparam/

[18] http://www.ebi.ac.uk/Tools/msa/clustalo/

[19] Istvan ES et al. Proc. Natl. Acad. Sci. 2011 108: 1627 [PMID: 21205898]

[20] Ender KL et al. J. Pediatr. Hematol. Oncol. 2011 33: 496 [PMID: 21941141]

[21] Meier ER et al. PLOS ONE 2015 10: e0136672 [PMID: 26366562]

Edited by $P$ Kangueane

Citation: Awasthi et al. Bioinformation 13(8): 269-273 (2017)

License statement: This is an Open Access article which permits unrestricted use, distribution, and reproduction in any medium, provided the original work is properly credited. This is distributed under the terms of the Creative Commons Attribution License 